\title{
Pelatihan Pembukuan dan Operasional Koperasi Madrasah Ibtidaiyah Dalam Rangka Perbaikan Kesejahteraan Guru Se-Kecamatan Secang, Kabupaten Magelang
}

\author{
Yustirania Septiani ${ }^{1}$ \\ Universitas Tidar, yustirania.septiani@gmail.com \\ Rr. Retno Sugiharti² \\ Universitas Tidar, retno.sugiharti@untidar.ac.id \\ Supanji Setyawan ${ }^{3}$ \\ Universitas Tidar, supanji@untidar.ac.id
}

\begin{abstract}
Abstrak
Faktor utama keberlangsungan Koperasi Sekolah adalah pengelolaan yang baik. Pengelolaan dalam koperasi sekolah melingkupi pengelolaan dari sisi pengorganisasian baik struktur organisasi maupun keuangan. Program Kemitraan Masyarakat ini bertujuan untuk memberikan pemahaman dan pelatihan kepada Guru Madrasah Ibtidaiyah se-Kecamatan Secang yang juga berperan sebagai pengelola Koperasi Sekolah terkait struktur organisasi dalam koperasi sekolah, penggunaan pembukuan menggunakan aplikasi serta sirkulasi operasional koperasi sekolah yang baik. Hal ini bertujuan agar Madrasah Ibtidaiyah se-Kecamatan Secang yang sudah memiliki koperasi sekolah mampu mengelola koperasi tersebut menjadi lebih terstruktur dan sistematis. Melalui pengabdian kepada masyarakat ini bertujuan juga untuk meningkatkan keberadaan Koperasi Sekolah sehingga dapat memberikan kontribusi pada peningkatan kesejahteraan guru sekolah tersebut. Pelaksanaan Program Kemitraan Masyarakat ini dilakukan dengan menggunakan metode ceramah, tutorial, dan diskusi yang diberikan intensif selama 3 kali pertemuan. Dari kegiatan ini diketahui bahwa rata-rata Koperasi Sekolah yang sudah ada belum berjalan dengan maksimal. Kendala utama yang dihadapi adalah kurangnya sumber daya pengelola koperasi. Terbatasnya jumlah guru di masingmasing sekolah membuat masing-masing guru telah mengemban tugas yang cukup banyak, sehingga pengelolaan koperasi sekolah sering terbengkalai. Namun dengan adanya otomatisasi pembukuan yang disampaikan pada kegiatan ini memudahkan guru sebagai pengelola koperasi sekolah untuk melakukan pencatatan transaksi di koperasi sekolah. Dari hasil evaluasi kegiatan, kegiatan pelatihan ini telah meningkatkan kemampuan pengelola koperasi sekolah dalam hal ini guru dalam melakukan pengelolaan koperasi khususnya dalam hal pembukuan keuangan.
\end{abstract}

Kata Kunci: Koperasi Sekolah, Pengelolaan, Sistem Pembukuan

\section{Abstract}

The main factor for the sustainability of School Cooperatives is good management. Management in school cooperatives encompasses management in terms of organizing both organizational and financial structures. This Community Partnership Program aims to provide understanding and training to Madrasah Ibtidaiyah teachers throughout Secang District who also participate as managers of School Cooperatives related to cooperative 
organizations in schools, using bookkeeping to use applications and assistance in good schools. This is intended so that Madrasah Ibtidaiyah in Secang Subdistrict which already has a school cooperative capable of managing this cooperative becomes more structured and systematic. Through community service, it must also improve the School Cooperative so that it can contribute to improving the welfare of the school teacher. The Community Partnership Implementation Program is carried out using lecture, tutorial and discussion methods which are given intensively during 3 meetings. The existing school cooperatives have not run optimally. The main obstacle that supports the cooperative management resources. The limited number of teachers in each school makes each teacher have to carry quite a lot of tasks, so that the management of school cooperatives is often neglected. But with the presence of bookkeeping automation delivered at this activity provided the teacher as manager of the school cooperative to record transactions at the school cooperative. From the results of the evaluation of the activity, this training increases the competence of school managers in this regard, the teacher in conducting cooperative management specifically in terms of financial accounting.

Keywords: School Cooperatives, Management, Accountancy System

\section{Pendahuluan}

Koperasi sekolah adalah koperasi yang beranggotakan siswa sekolah yaitu pada jenjang pendidikan dasar dan pendidikan menengah atau pendidikan setara dengan itu. Dasar hukum pendirian koperasi mengacu pada surat keputusan Menteri Tenaga Kerja, Transmigrasi, dan Koperasi, Nomor 638/SKPTS/men/1974. Kekhasan koperasi sekolah adalah koperasi yang didalam keanggotaannya adalah murid sekolah tersebut dengan pengurus adalah guru dari sekolah tersebut. Fungsi koperasi sekolah hadir sebagai wadah dalam mendidik kesadaran berkoperasi di kalangan anggota yaitu siswa sekolah. Selain itu keberadaan koperasi sekolah akan untuk mengajarkan siswa dalam mengembangkan sifat dalam wirausaha kepada siswa sejak dini serta untuk membantu memenuhi kebutuhan siswa.

Manfaat pada koperasi sekolah sudah pasti sangat dirasakan para siswa. Dengan adanya sebuah koperasi sekolah para siswa akan siswa akan mendapat banyak pengalaman dalam praktik langsung berkoperasi antara lain melakukan pendirian koperasi, menyelenggarakan rapat anggota koperasi, membuat rencana kerja, rencana anggaran pendapatan belanja koperasi, mempraktikan pembukuan dan pengadministrasian kegiatan usaha koperasi secara cermat dan teliti, mempraktikan kerjasama dalam usaha, mengawasi kegiatan usaha koperasi. Dari rangkaian kegiatan dalam koperasi sekolah pada akhirnya diharapkan akan membentuk karakter tanggung jawab pada diri siswa (Sikidjo, Muhson dan Mustofa, 2016).

Melihat banyaknya manfaat yang bisa diambil dari pendirian koperasi sekolah yang bisa dirasakan, maka penting untuk melakukan pendampingan koperasi sekolah khususnya bagi Madrasah Ibtidaiyah se-kecamatan Secang. Selain untuk menjaga keberlangsungan keberadaan Koperasi Sekolah yang sudah ada, tentu akan meningkatkan kesejahteraan anggota dan pengurus Koperasi Sekolah.

Namun ada beberapa kendala yang dihadapi pengelola koperasi sekolah dalam hal ini guru dalam melakukan pengelolaan koperasi sekolah. Berdasarkan hasil wawancara kepada pihak ketua K3M (Kelompok Kerja Kepala Madrasah) diketahui 
masih banyak Madrasah Ibtidaiyah di Kecamatan Secang masih kesulitan dalam mengelola Koperasi Sekolah. Hal ini disebabkan karena minimnya guru tetap di Madrasah Ibtidaiyah kecamatan Secang. Presentase guru tetap dengan guru honorer masih sangat tidak seimbang, yaitu dengan perbandingan 1:4. Selain itu, guru honorer umumnya berpenghasilan masih jauh dari UMR, hal ini menyebabkan guru honorer tidak dapat fokus dalam kegiatan non pembelajaran sekolah. Kondisi tersebut mendorong guru honorer untuk memperoleh tambahan penghasilan, yang biasanya dilakukan dengan bekerja di Madrasah lainnya agar memenuhi jam kerja yakni 24 tatap muka. Di sisi lain Guru tetap yang hanya 1-3 orang di tiap Madrasah Ibtidaiyah menjadikan kendala untuk pembentukan dan pengorganisasian koperasi sekolah karena pengelola yang terbatas. Selain itu, banyaknya tugas guru yang melekat menjadi beban tersendiri. Juga, siswa di Madrasah Ibtidaiyah adalah siswa sekolah dasar, tentu akan membutuhkan pengelolaan yang berbeda, hal ini terkait dengan pemahaman anak terkait pembukuan yang masih sangat minim bila dibandingkan dengan koperasi sekolah yang berada di sekolah menengah pertama atau sekolah menengah atas.

Koperasi Sekolah yang telah didirikan di Madrasah Ibtidaiyah se-kecamatan Secang saat ini masuk ke dalam tahap pengelolaan. Oleh karena itu dibutuhkan suatu pemahaman atas pengelolaan Koperasi Sekolah yang sistematis dan terstruktur dalam pengelolaan organisasi maupun pengelolaan keuangan/ pembukuan. Hal ini tentu akan memudahkan pengelola koperasi dalam hal ini adalah guru untuk melakukan pengelolaan atas koperasi sekolah yang dikelola. Dengan pengelolaan yang baik tentunya akan dapat meningkatkan output dan outcome bagi pengelola (pada khususnya) dan bagi sekolah yang bersangkutan (pada umumnya)

Dari paparan tersebut, maka permasalahan prioritas mitra dalam hal ini Madrasah Ibtidaiyah se-Kecamatan Secang antara lain:

1. Masih belum adanya struktur organisasi dalam koperasi sekolah menyebabkan masih banyak madrasah ibtidaiyah se-Kecamatan Secang yang belum mampu mengkoordinasikan dengan baik

2. Masih belum adanya pendamping tentang pengelolaan koperasi sekolah melalui pembukuan berbasis aplikasi

3. Masih minimnya sirkulasi operasional terkait pengeluaraan dan pengecekan barang dagangan koperasi

Tujuan dan Manfaat dari pengabdian kepada masyarakat ini antara lain:

1. Memperbaiki struktur organisasi agar tiap Madrasah Ibtidaiyah mampu berkoordinasi lebih baik terkait koperasi sekolah

2. Penggunaan pembukuan yang berbasis aplikasi akan memudahkan para pengelola koperasi sekolah dalam menentukan harga dan melihat keuntungan yangditerima oleh koperasi sekolah

3. Peningkatan pengelolaan mengenai sirkulasi operasi akan memudahkan dalam melakukan arus pengeluaran dan pengecekan barang dagangan koperasi

Kegiatan pengabdian kepada masyarakat ini akan dilaksanakan dengan peserta dari 23 Madrasah Ibtidaiyah Se-Kecamatan Secang, tiap Madrasah Ibtidaiyah 
mewakilkan pengelola koperasi atau calon pengelola koperasi sekolah 1-2 orang. Kegiatan ini bertempat di PPA Kecamatan Secang. Pelaksanaan kegiatan akan dilaksanakan pada 17,24 Juli 2019 dan 7 Agustus 2019.

\section{Metode Pengabdian}

Pelaksanaan Program Kemitraan Masyarakat ini dilakukan dengan menggunakan metode ceramah, tutorial, dan diskusi. Adapun sistematika pelaksanaan kegiatan pengabdian ini adalah sebagai berikut:

1. Langkah 1 (Metode Ceramah):

Peserta diberikan pendampingan berupa pembentukan struktur organisasi koperasi

2. Langkah 2 (Metode Tutorial):

Peserta pelatihan diberikan materi tentang pembukuan koperasi berbasis aplikasi yang memudahkan dalam pengkontrolan keuangan

3. Langkah 3 (Metode Diskusi):

Peserta pelatihan diberikan kesempatan untuk mendiskusikan permasalahan yang berkaitan dengan sistem pembukuan dan sirkulasi operasional yang baik untuk diterapkan di koperasi.

Kegiatan dimulai dengan tahap persiapan kegiatan yaitu perancangan pelaksanaan kegiatan yang meliputi rapat koordinasi bersama ketua K3M (Kelompok Kerja Kepala Madrasah), survei lokasi pelatihan, pelaksanaan kegiatan, monitoring dan evaluasi program. Materi yang diberikan, disampaikan dalam 3 (tiga) tahap, yaitu:

Tabel 1 Materi yang disampaikan

\begin{tabular}{|c|c|c|}
\hline No & Materi & Detail \\
\hline 1. & Pertemuan 1: Materi 1 & $\begin{array}{l}\text { Pembentukan Struktur Organisasi pada } \\
\text { Koperasi Sekolah }\end{array}$ \\
\hline 2. & Pertemuan 2: Materi 2 & $\begin{array}{l}\text { Pembukuan/pencatatan transaksi di } \\
\text { Koperasi Sekolah menggunakan Aplikasi } \\
\text { Akuntansi pada Ms. Excel. } \\
\text { Aplikasi pembukuan yang diberikan kepada } \\
\text { peserta dapat disesuaikan dengan } \\
\text { kebutuhan di masing-masing koperasi } \\
\text { sekolah yang dikelola peserta }\end{array}$ \\
\hline 3. & Pertemuan 3: Materi 3 & Sirkulasi Operasional Koperasi Sekolah \\
\hline
\end{tabular}

Dalam kegiatan ini partisipasi mitra dalam kegiatan pengabdian masyarakat berupa antara lain:

1. Kehadiran peserta dalam kegiatan pendampingan

2. Keaktifan peserta dalam melakukan konsultasi

3. Peserta menggunakan aplikasi pembukuan sederhana

4. Peserta menggunakan sirkulasi operasionl dalam studi kasus yang diberikan Pada akhirnya, program ini dikatakan berhasil jika Madrasah Ibtidaiyah seKecamatan Secang memahami pembentukan struktur organisasi koperasi yang baik, 
dapat menggunakan aplikasi pembukuan untuk kegiatan koperasi dan model sirkulasi operasional yang baik dalam koperasi.

\section{Hasil dan Pembahasan}

Hasil yang telah dicapai dalam kegiatan Pelatihan Pembukuan Dan Operasional Koperasi Madrasah Ibtidaiyah Dalam Rangka Perbaikan Kesejahteraan Guru SeKecamatan Secang, Kabupaten Magelang

1. Peserta guru Madrasah Ibtidaiyah se-kecamatan Secang Kabupaten Magelang mengetahui struktur koperasi yang seharusnya ada dalam pembentukan koperasi

2. Peserta guru Madrasah Ibtidaiyah se-kecamatan Secang Kabupaten Magelang mengetahui penggunaan sistem pembukuan yang sederhana yang dapat diaplikasikan dalam koperasi sekolah, sehingga mampu memantau pengeluaran dan pendapatan mereka.

3. Peserta guru Madrasah Ibtidaiyah se kecamatan Secang Kabupaten Magelang mengetahui bentuk sirkulasi operasional koperasi sekolah yang seharusnya diterapkan disekolah masing-masing Ilustrasi hasil penelitian dapat berupa grafik/tabel/gambar yang diberi keterangan secukupnya agar mudah dimengerti.

Beberapa foto dokumentasi kegiatan adalah sebagai berikut:

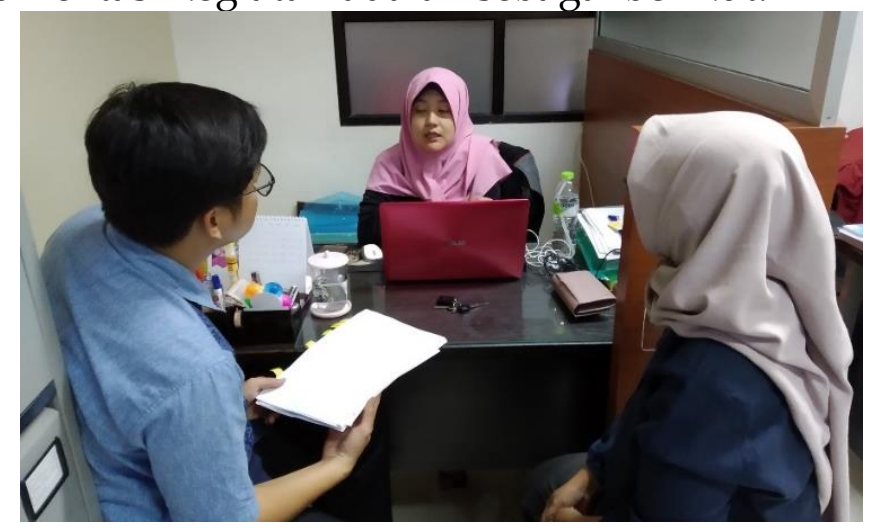

Gambar 1 Rapat Koordinasi Tim Pengabdian

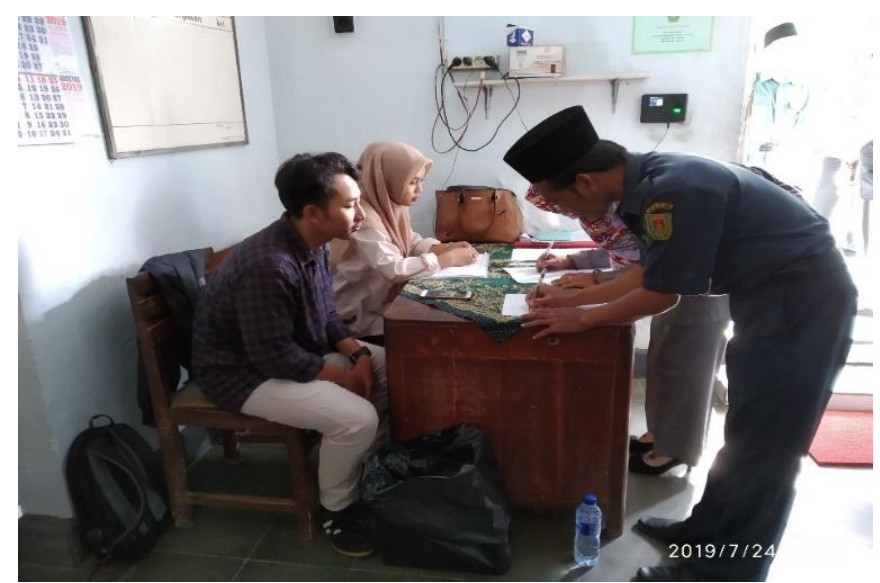

Gambar 2 Registrasi Peserta 


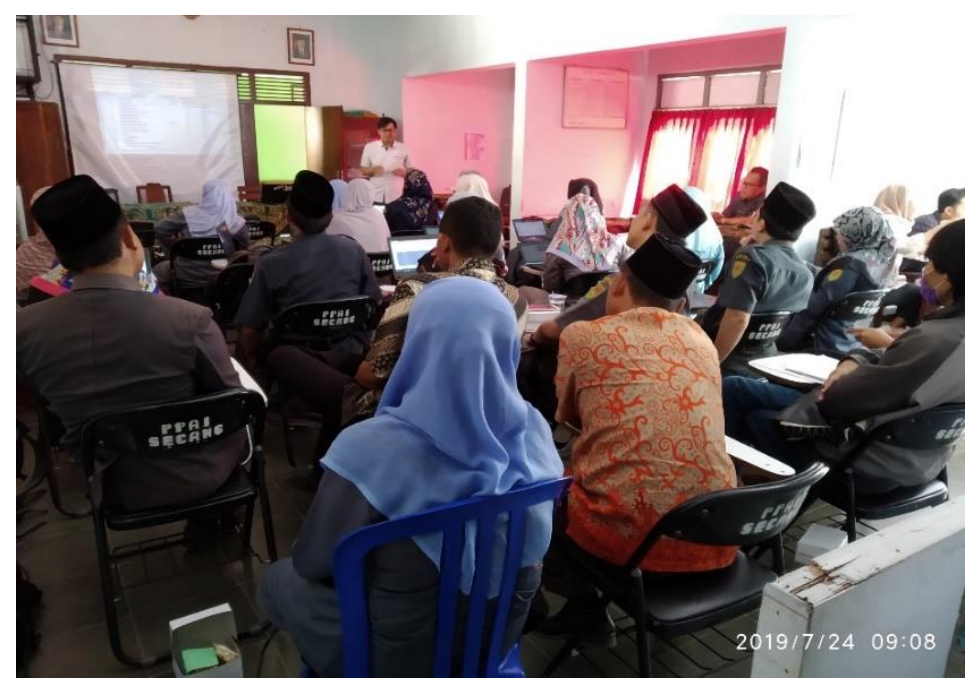

Gambar 3 Kegiatan Pelatihan

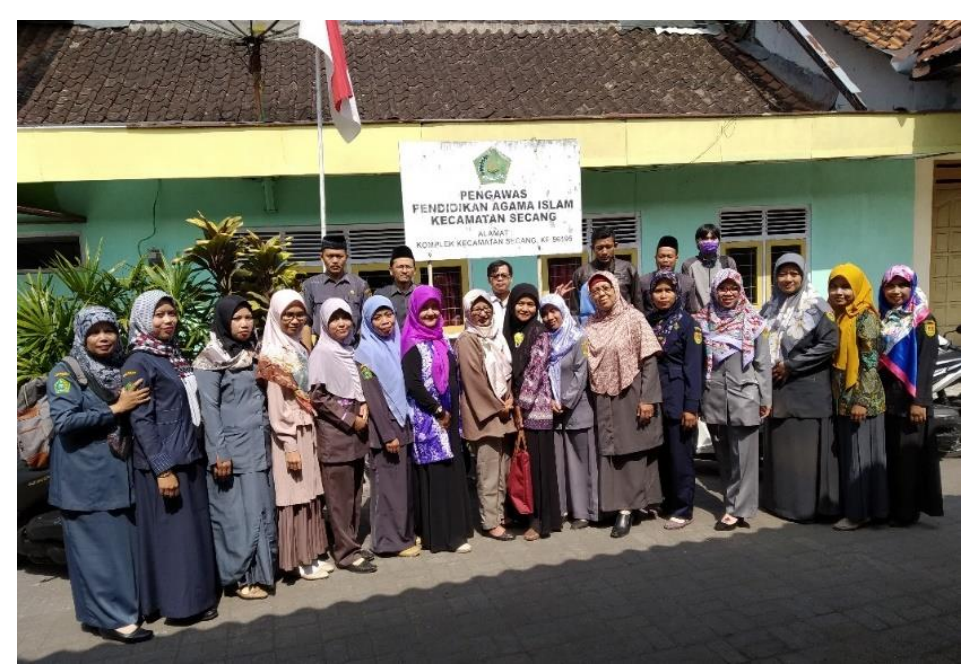

Gambar 4 Foto Bersama

Dari hasil diskusi dengan peserta selama kegiatan berlangsung ada beberapa informasi yang dapat dikumpulkan oleh Tim Pengabdian, yaitu: ada beberapa kendala yang dihadapi dalam pengelolaan koperasi sekolah di Madrasah Ibtidaiyah secara umum, yaitu dari sisi siswa sekolah sebagai anggota, nyatanya peran siswa dalam pengorganisasian koperasi sekolah belum terlibat secara langsung. Hal ini terkait dengan siswa di Madrasah Ibtidaiyah yang masih pada level pendidikan dasar. Selain itu dari sisi sarana dan prasarana untuk koperasi sekolah dirasa belum lengkap, juga masih ada kendala dalam kecukupan modal. Maka tidak heran apabila dari hasil wawancara dengan peserta pelatihan diperoleh informasi bahwa beberapa sekolah masih terkesan apa-adanya. Juga hingga saat ini belum ada monitoring dari dinas terkait.

Maka dari itu, ada beberapa hal yang bisa dilakukan antara lain: meningkatkan sosialisasi tentang keberadaan Koperasi Sekolah sehingga tidak menutup kemungkinan adanya investasi yang masuk ke koperasi sekolah yang akan dapat menambah modal bagi koperasi sekolah. Dalam hal kebutuhan monitoring, perlu 
dilakukan kerjasama dengan dinas terkait khususnya Dinas Perdagangan, Koperasi dan UKM Kabupaten Magelang. Dengan adanya kerjasama akan memungkinkan untuk mengadakan pelatihan, monitoring dan bimbingan secara terprogram dan lebih intensif dalam pengelolaan koperasi. Dalam usaha peningkatan kapasitas koperasi sekolah, salah satu strategi yang dapat digunakan yaitu membentuk tim guru Pembina yang bertanggung jawab atas keberadan koperasi,mengaktualisasi potensi sekolah dalam memfasilitasi keberadaan koperasi sekolah sebagai miniatur kehidupan berkoperasi bagi para siswa yang anggota-anggotanya adalah para siswa dengan menjalankan visi dan misinya (Sari, 2013)

\section{Simpulan dan Rekomendasi}

Dari kegiatan ini dapat disimpulkan bahwa Peserta guru Madrasah Ibtidaiyah sekecamatan Secang Kabupaten Magelang menjadi memahami peran struktur organisasi koperasi sekolah dalam sebuah tempat pendidikan dalam hal ini sekolah formal. Selain itu, peserta guru Madrasah Ibtidaiyah se-Kecamatan Secang Kabupaten Magelang juga sudah mengetahui pengaplikasian sistem pembukuan secara sederhana sehingga proses pembukuan keuangan koperasi sekolah yang dikelola menjadi lebih mudah dan teratur (dengan bantuan aplikasi) serta peserta guru Madrasah Ibtidaiyah se-Kecamatan Secang Kabupaten Magelang sudah mengetahui bentuk pengelolaan/manajemen koperasi sekolah yang dapat diterapkan di sekolah masing-masing.

Rencana tahapan berikutnya yaitu masih diperlukan pendampingan mengenai pembentukan struktur organisasi koperasi sekolah, pembuatan pembukuan dengan aplikasi serta cara mengelola koperasi sekolah. Diharapkan dengan adanya pengelolaan yang baik dalam koperasi sekolah terutama di Madrasah Ibtidaiyah sekecamatan Secang Kabupaten Magelang ini mampu memberikan nilai tambah dari kegiatan jual-beli di koperasi sekolah sehingga akan dapat meningkatkan kesejahteraan guru dan juga pelatihan bagi siswa sekolah terkait kewirausahaan.

\section{Daftar Pustaka}

Sudarsono dan Edilius. 2008. Manajemen Koperasi Indonesia. Jakarta : Rineka Cipta.

Sukidjo, Sukidjo; Muhson, Ali; Mustofa, Mustofa. 2016. Cooperative Student for Developing Students Character. Jurnal Economia, [S.1.], v. 12, n. 2, p. 122-134. ISSN 2460-1152.

Suryobroto. 2006. Proses Belajar Mengajar di Sekolah. Jakarta: PT Rineka Cipta

Sari, Aprilia Dea. 2013. Efektivitas Peran Koperasi Sekolah Sebagai Unit Pembelajaran Kewirausahaan Di Smp Negeri 1 Karanganyar Kabupaten Pekalongan. Economic Education Analysis Journal, 2(1).

Tjiptono, F dan A. Diana. 2001. Total Quality Management. Penerbit Andi. Yogyakarta. 
Undang-Undang Republik Indonesia Nomor 25 tahun 1992 Pasal 1 dan 3 Tentang Koperasi Indonesia

Widayanti, N. 1992. Dinamika Koperasi. Jakarta: PT.Gramedia Pustaka Umum.

Zubaidah. 2007. Manajemen Syariah Koperasi. Disampaikan dalam Pelatihan Manajemen Bisnis untuk Ikatan Pengusaha Aisyiyah (IPAS) yang Diselenggarakan oleh Majelis 